\title{
Fabrication of a New Porous Glass-Ceramic Monolith Using Vanadium(III) Calcium Phosphate Glass as Precursor
}

\author{
Italo Odone Mazali* and Oswaldo Luiz Alves \\ Instituto de Química, Universidade Estadual de Campinas, CP 6154, 13084-971 Campinas, SP - Brazil
}

\begin{abstract}
Resultados preliminares de XRD, IR, Raman e SEM mostraram que monólitos vitrocerâmicos porosos (pgc-LVCP) com esqueleto tridimensional constituído pelas fases $\mathrm{V}\left(\mathrm{PO}_{3}\right)_{3}$ e $\mathrm{Ca}_{3}\left(\mathrm{VO}_{4}\right)_{2}$ foram obtidos utilizando um vidro original de $\mathrm{Li}_{2} \mathrm{O}-\mathrm{V}_{2} \mathrm{O}_{3}-\mathrm{CaO}-\mathrm{P}_{2} \mathrm{O}_{5}$ como precursor. O pgc-LVCP pode ser um hospedeiro poroso promissor para sistemas químicos integrados visto que a fase $\mathrm{Ca}_{3}\left(\mathrm{VO}_{4}\right)_{2}$ apresenta propriedades ferroelétricas e de luminescência enquanto a fase $\mathrm{V}\left(\mathrm{PO}_{3}\right)_{3}$ exibe propriedades magnéticas associadas com elevada estabilidade mecânica, química e térmica.
\end{abstract}

Preliminary XRD, IR, Raman and SEM data indicate that porous glass-ceramic monoliths (pgcLVCP) with skeleton of $\mathrm{V}\left(\mathrm{PO}_{3}\right)_{3}$ and $\mathrm{Ca}_{3}\left(\mathrm{VO}_{4}\right)_{2}$ with three-dimensional network structure using an original $\mathrm{Li}_{2} \mathrm{O}-\mathrm{V}_{2} \mathrm{O}_{3}-\mathrm{CaO}-\mathrm{P}_{2} \mathrm{O}_{5}$ glass as precursor was obtained. The pgc-LVCP is a promising porous host for integrated chemical systems because the $\mathrm{Ca}_{3}\left(\mathrm{VO}_{4}\right)_{2}$ has ferroelectric and luminophor properties while $\mathrm{V}\left(\mathrm{PO}_{3}\right)_{3}$ exhibits magnetic properties associated with high degree of mechanical, chemical and thermal stability.

Keywords: porous materials, vanadium metaphosphate, calcium orthovanadate, vanadium glass, devitrification

\section{Introduction}

Porous materials are extremely important in the fields of nanotechnology, integrated chemical systems, and cooperative interactions in reactions performed in confined environment. ${ }^{1-4}$ There is an increasing interest in designing and developing porous materials with stable porous texture for high-temperature separation and catalytic applications. ${ }^{5}$ It has been demonstrated that every property of nanophase materials is interesting for various technological applications because of the specifically sizerelated properties of crystalline domains or crystallites. In integrated chemical systems (ICS), the pore size of a support material determines the maximum size of the particle synthesized within it. ${ }^{2,6}$ The pores that typify these structures can be considered as 'micro-chambers', which fulfill, at the same time, a template role. ${ }^{7,8}$ The size, the morphology and the reactivity of the particle will depend on the dimensions, morphology, texture and chemical nature of the surface of pores.

As alternative to the silica skeleton, Kokubu and Yamane prepared a porous glass-ceramic with $\mathrm{TiO}_{2}$-rich skeleton by thermal treatment and posterior leaching of

*e-mail:mazali@iqm.unicamp.br the $\mathrm{TiO}_{2}-\mathrm{SiO}_{2}-\mathrm{Al}_{2} \mathrm{O}_{3}-\mathrm{B}_{2} \mathrm{O}_{3}-\mathrm{CaO}-\mathrm{MgO}$ glass. ${ }^{9} \mathrm{~A}$ spinoidaltype phase separation takes place during a two-step heat treatment of $6 \mathrm{Li}_{2} \mathrm{O}-24 \mathrm{TiO}_{2}-39 \mathrm{CaO}-31 \mathrm{P}_{2} \mathrm{O}_{5}$ glasses yielding $\mathrm{LiTi}_{2}\left(\mathrm{PO}_{4}\right)_{3}, \mathrm{TiO}_{2}, \mathrm{Li}(\mathrm{TiO}) \mathrm{PO}_{4}, \beta-\mathrm{Ca}_{3}\left(\mathrm{PO}_{4}\right)_{2}$ and $\beta$ - $\mathrm{Ca}_{2} \mathrm{P}_{2} \mathrm{O}_{7}$ phases. ${ }^{10,11}$ Subsequent acid leaching removes the three last phases from the dense glass-ceramic and, as a result, a network of channels extends through the $\mathrm{LiTi}_{2}\left(\mathrm{PO}_{4}\right)_{3}$ with $\mathrm{TiO}_{2}$, as a minor phase. Recently, the preparation of a porous glass-ceramic with skeleton of $\alpha-\mathrm{NbPO}_{5}$ with three-dimensional network structure from the glass system $\mathrm{Li}_{2} \mathrm{O}-\mathrm{Nb}_{2} \mathrm{O}_{5}-\mathrm{CaO}-\mathrm{P}_{2} \mathrm{O}_{5}$ was reported. ${ }^{12,13}$ This was the first example, in the literature, of the preparation of a porous glass-ceramic where the devitrification occurs by surface crystallization, through heterogeneous nucleation.

The aim of this work was the fabrication and characterization of a porous glass-ceramic using an original vanadium(III) calcium phosphate glass as precursor. The phosphate framework exhibits great ability to stabilize reduced oxidation states because the relatively high charge in the $\mathrm{PO}_{4}^{3-}$ tetrahedral favors the formation of anionic frameworks with high degree of mechanical, chemical and thermal stability. ${ }^{14}$ Additionally, it is quite rare to find glassy porous materials other than siliceous materials. 


\section{Experimental}

Original glass samples of nominal composition $6 \mathrm{Li}_{2} \mathrm{O}-$ $18 \mathrm{~V}_{2} \mathrm{O}_{3}-43 \mathrm{CaO}-33 \mathrm{P}_{2} \mathrm{O}_{5}$ (mol \%), g-LVCP, were prepared by melting reagent grade $\mathrm{Li}_{2} \mathrm{CO}_{3}, \mathrm{CaCO}_{3}, \mathrm{~V}_{2} \mathrm{O}_{3}$ and $\mathrm{P}_{2} \mathrm{O}_{5}$ in a platinum crucible at $1450{ }^{\circ} \mathrm{C}$ for $1 \mathrm{~h}$ under air. The melt was poured onto carbon plates and annealed at $490^{\circ} \mathrm{C}$ for $2 \mathrm{~h}$ (the glass transition temperature, $\mathrm{T}_{\mathrm{g}}$, is equal to $530^{\circ} \mathrm{C}$ ). Glass-ceramic samples (gc-LVCP) were prepared by a thermal treatment of the glass plates at $530{ }^{\circ} \mathrm{C}$ for $20 \mathrm{~h}$ (nucleation step) and subsequently at $600{ }^{\circ} \mathrm{C}$ for $12 \mathrm{~h}$ (crystallization step; the crystallization temperature, $\mathrm{T}_{c}$, is equal to $600{ }^{\circ} \mathrm{C}$ for g-LVCP for a heating rate of $10{ }^{\circ} \mathrm{C} \mathrm{min}^{-1}$ ). The resulting glass-ceramics (gc-LVCP) was immersed in $1.0 \mathrm{~mol} \mathrm{~L}^{-1} \mathrm{HCl}$ aqueous solution and kept for $24 \mathrm{~h}$ at room temperature, in order to obtain porous glass-ceramic (pgc-LVCP).

Powder X-ray diffraction (XRD) patterns were obtained using a Shimadzu XRD6000 diffractometer, with Ni filters and $\mathrm{CuK} \alpha$ radiation, using $30 \mathrm{kV}$ and $20 \mathrm{~mA}$, calibrated with $\mathrm{Si}$ at a $2 \% \mathrm{~min}$ rate. Infrared spectra (IR) of $\mathrm{KBr}$ pellets were measured with a Perkin Elmer 1600 FTIR in the 1400$400 \mathrm{~cm}^{-1}$ range, with a resolution of $2 \mathrm{~cm}^{-1}$. The Raman spectra were recorded on a Renishaw System 3000 Raman Imaging Microscope ( $c a .1 \mu \mathrm{m}$ spatial resolution) using a He-Ne laser $(632.8 \mathrm{~nm})$ and $8 \mathrm{~mW}$ of power before the entrance optics. Scanning electron microscope (SEM) was performed by using a JEOL JSM T-300 Microscope. The density of pg-LVCP and pgc-LVCP were measured by the Archimedes's method using deionized water as the buoyancy liquid at $25^{\circ} \mathrm{C}$.

\section{Results and Discussion}

The crystalline phases of the glass-ceramic before and after acid leaching were characterized by X-ray powder diffraction (XRD), infrared (IR) and Raman spectroscopies. In spite of the very close interplanar distances, the XRD pattern (Figure 1) suggested the presence of the following phases in dark green gc-LVCP: $\beta$ - $\mathrm{Ca}_{2} \mathrm{P}_{2} \mathrm{O}_{7}{ }^{15}, \beta-\mathrm{Ca}_{2} \mathrm{~V}_{2} \mathrm{O}_{7}{ }^{16}$, $\beta-\mathrm{Ca}_{3}\left(\mathrm{PO}_{4}\right)_{2}{ }^{15}, \mathrm{Ca}_{3}\left(\mathrm{VO}_{4}\right)_{2}{ }^{15}, \mathrm{~V}\left(\mathrm{PO}_{3}\right)_{3}{ }^{15}, \mathrm{VPO}_{4}{ }_{4}^{15}$ and $\mathrm{LiCaPO}_{4}{ }^{15}$ phases. The dark green color of the gc-LVCP is due the occurrence of the $\mathrm{V}\left(\mathrm{PO}_{3}\right)_{3}$ and $\beta-\mathrm{Ca}_{2} \mathrm{~V}_{2} \mathrm{O}_{7}$ phases. The phases identified show mixed valence state vanadium, but the presence of $\mathrm{V}\left(\mathrm{PO}_{3}\right)_{3}$ and $\mathrm{VPO}_{4}$ phases confirms the stabilization of vanadium as $\mathrm{V}$ (III). In the XRD pattern of the pgc-LVCP, the absence of peaks at $27.0^{\circ}, 28.5^{\circ}$ and $33.5^{\circ}(2 \theta)$ confirms the leaching of the $\beta-\mathrm{Ca}_{2} \mathrm{P}_{2} \mathrm{O}_{7}$, $\beta-\mathrm{Ca}_{2} \mathrm{~V}_{2} \mathrm{O}_{7}$ and $\mathrm{LiCaPO}_{4}$ phases, respectively. The leaching of the $\mathrm{VPO}_{4}$ phase is confirmed by the absence of peaks at $24.8^{\circ}$ and $35.4^{\circ}(2 \theta)$ in pgc-LVCP.

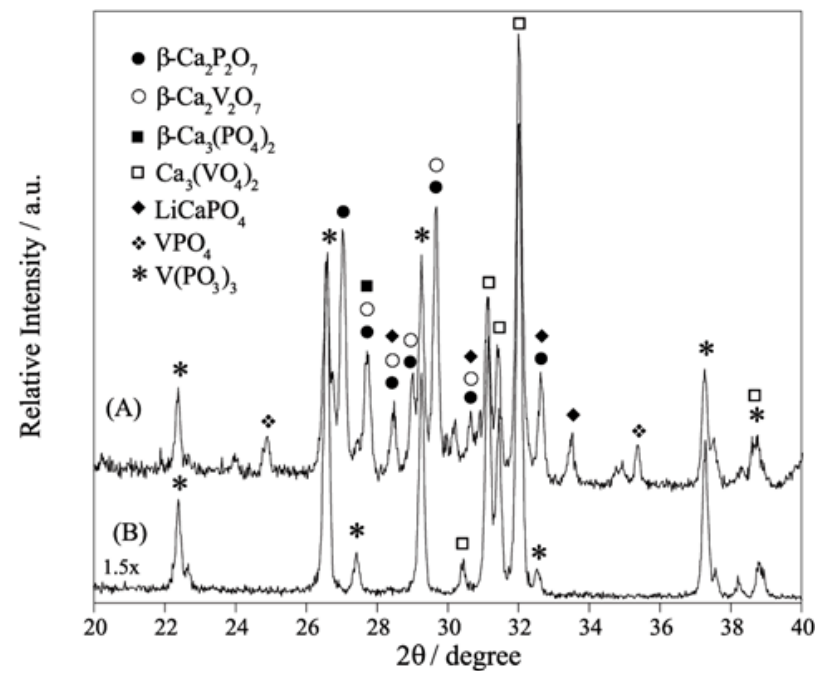

Figure 1. Powder XRD patterns of (A) gc-LVCP and (B) pgc-LVCP.

The IR spectrum of gc-LVCP sample (Figure 2) confirmed the presence of pyrophosphate groups, characterized by the following typical modes: $v\left(\mathrm{PO}_{3}\right)_{\text {asym }}$ (between $1210 \mathrm{~cm}^{-1}$ and $\left.1100 \mathrm{~cm}^{-1}\right), v\left(\mathrm{PO}_{3}\right)_{\text {sym }}$ (between $1065 \mathrm{~cm}^{-1}$ and $1000 \mathrm{~cm}^{-1}$ ), $v(\mathrm{P}-\mathrm{O}-\mathrm{P})_{\text {asym }}\left(972 \mathrm{~cm}^{-1}\right.$ and $\left.944 \mathrm{~cm}^{-1}\right)$ and especially by the band at $725 \mathrm{~cm}^{-1}$, characteristic of the $\beta-\mathrm{Ca}_{2} \mathrm{P}_{2} \mathrm{O}_{7} v(\mathrm{P}-\mathrm{O}-\mathrm{P})_{\text {sym }}$ mode. ${ }^{17}$ The occurrence of this group is also confirmed by Raman spectroscopy (Figure 3), with a band at $737 \mathrm{~cm}^{-1}$ $\left[v\left(\mathrm{PO}_{3}\right)_{\text {sym }}\right]$. The occurrence of the $\beta-\mathrm{Ca}_{2} \mathrm{~V}_{2} \mathrm{O}_{7}$ phase is confirmed by the presence of bands of $\mathrm{V}_{2} \mathrm{O}_{7}{ }^{4}$ groups: at $874 \mathrm{~cm}^{-1}$ (IR) and $880 \mathrm{~cm}^{-1}$ (Raman) attributed to $v_{\mathrm{q} 4}(\mathrm{~V}-\mathrm{O})$ and by IR bands at $815 \mathrm{~cm}^{-1}\left[v_{\mathrm{q} 6, \mathrm{q} 7}(\mathrm{~V}-\mathrm{O})\right], 530 \mathrm{~cm}^{-1}$ and $472 \mathrm{~cm}^{-1}\left[v(\mathrm{~V}-\mathrm{O}-\mathrm{V})_{\mathrm{sym}}\right] .{ }^{18}$ In the $\mathrm{gc}-\mathrm{LVCP}$, there is overlapping of the $\mathrm{Ca}_{3}\left(\mathrm{VO}_{4}\right)_{2}$ and $\beta-\mathrm{Ca}_{3}\left(\mathrm{PO}_{4}\right)_{2}$ bands in IR spectra, but the Raman spectra permit distinguishing between these isostructural phases. The Raman bands in $\mathrm{Ca}_{3}\left(\mathrm{VO}_{4}\right)_{2}$ are distributed in only two wavenumber regions relating to the $v(\mathrm{~V}-\mathrm{O})$ modes $\left(950-750 \mathrm{~cm}^{-1}\right.$; observed at $900 \mathrm{~cm}^{-1}$ as a very strong band in both gc-LVCP and pgc-LVCP) and $\delta(\mathrm{O}-\mathrm{V}-\mathrm{O})$ modes mixed with the translational and rotational modes of the $\mathrm{VO}_{4}^{3-}$ groups as well as $\mathrm{Ca}^{2+}$ cations displacements $\left(50-450 \mathrm{~cm}^{-1}\right){ }^{19}$ The Raman bands in $\beta-\mathrm{Ca}_{3}\left(\mathrm{PO}_{4}\right)_{2}$ are distributed in five distinct wavenumber ranges: $170-305,405-483,547-631,946-970$, and 1005$1091 \mathrm{~cm}^{-1}$, corresponding to the lattice modes and, $v_{2}, v_{4}, v_{1}$ and $v_{3}$ internal modes of the $\mathrm{PO}_{4}^{3-}$ ions, respectively. ${ }^{19}$ The IR and Raman spectra of the pgc-LVCP are simpler, in comparison to these of gc-LVCP. The acid leaching of the $\beta-\mathrm{Ca}_{2} \mathrm{P}_{2} \mathrm{O}_{7}$ and $\beta-\mathrm{Ca}_{2} \mathrm{~V}_{2} \mathrm{O}_{7}$ phases were confirmed by the absence of bands at $725 \mathrm{~cm}^{-1}$ (IR) and $737 \mathrm{~cm}^{-1}$ (Raman); and at $880 \mathrm{~cm}^{-1}$ (Raman), respectively. The occurrence of the $\beta-\mathrm{Ca}_{3}\left(\mathrm{PO}_{4}\right)_{2}$ phase is confirmed by presence and subsequent absence of Raman bands at 572, 600 and 652 $\mathrm{cm}^{-1}$ before and after leaching, respectively. pgc-LVCP 
exhibits a bright green color due the presence of $\mathrm{V}\left(\mathrm{PO}_{3}\right)_{3}$, confirmed by the peaks at $22.5^{\circ}, 26.5^{\circ}, 29.2^{\circ}$ and $37.2^{\circ}(2 \theta)$ in the XRD pattern (Figure 1). The $\mathrm{V}\left(\mathrm{PO}_{3}\right)_{3}$ phase can be described as being formed from isolated $\mathrm{VO}_{6}$ octahedra linked through infinite $\left[\mathrm{PO}_{3}\right]_{\mathrm{f}}$ chains of $\mathrm{PO}_{4}$ tetrahedra. Each $\mathrm{VO}_{6}$ group is bridged to six neighbouring $\mathrm{VO}_{6}$ by phosphate groups. These lie in one of the two adjacent layers and lead to three dimensional bonding. The $\mathrm{V}^{3+}-\mathrm{O}$ bond length, in $\mathrm{VO}_{6}$ geometry, is moderately distorted. ${ }^{14}$ Higher valence vanadium systems are characterized by the short vanadyl bond $(\mathrm{V}=\mathrm{O})$ responsible for a highly intense Raman band at $994 \mathrm{~cm}^{-1} .^{20}$ The absence of this band in both gc-LVCP and pgc-LVCP confirmed the occurrence of $\mathrm{V}\left(\mathrm{PO}_{3}\right)_{3}$.

Scanning electron microscopy (SEM) of the fracture face confirmed the porous structure of the pgc-LVCP, which exhibits a popsicle-like structure (Figure 4), as a

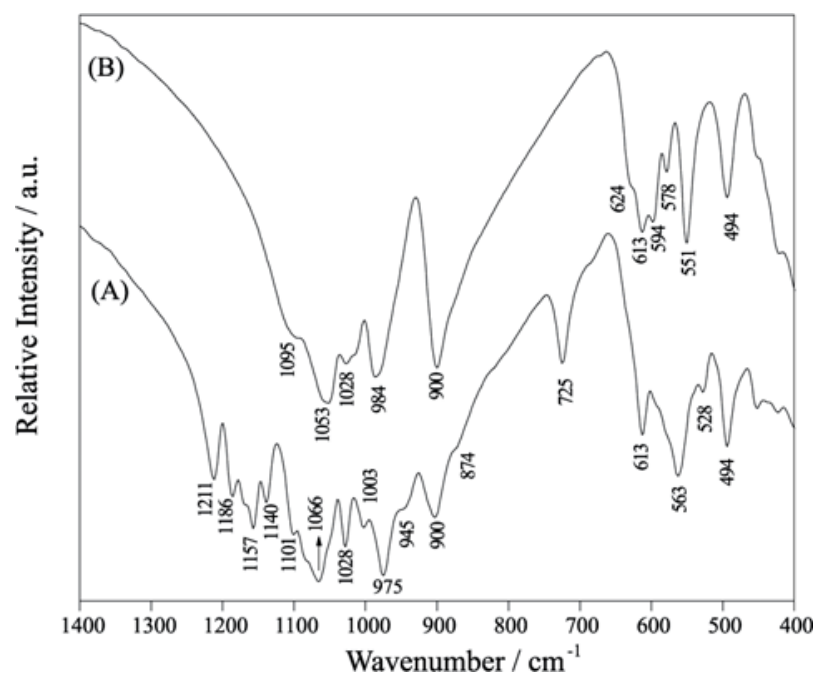

Figure 2. Infrared spectra of (A) gc-LVCP and (B) pgc-LVCP.

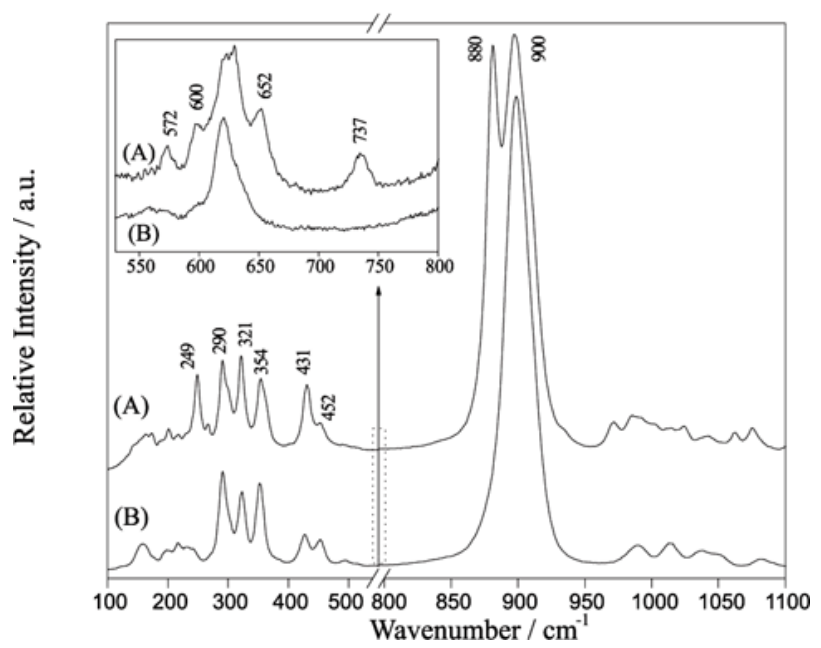

Figure 3. Raman spectra of (A) gc-LVCP and (B) pgc-LVCP. consequence of devitrification that occurs by surface crystallization and the process proceeds from the surface to the bulk of the specimen.
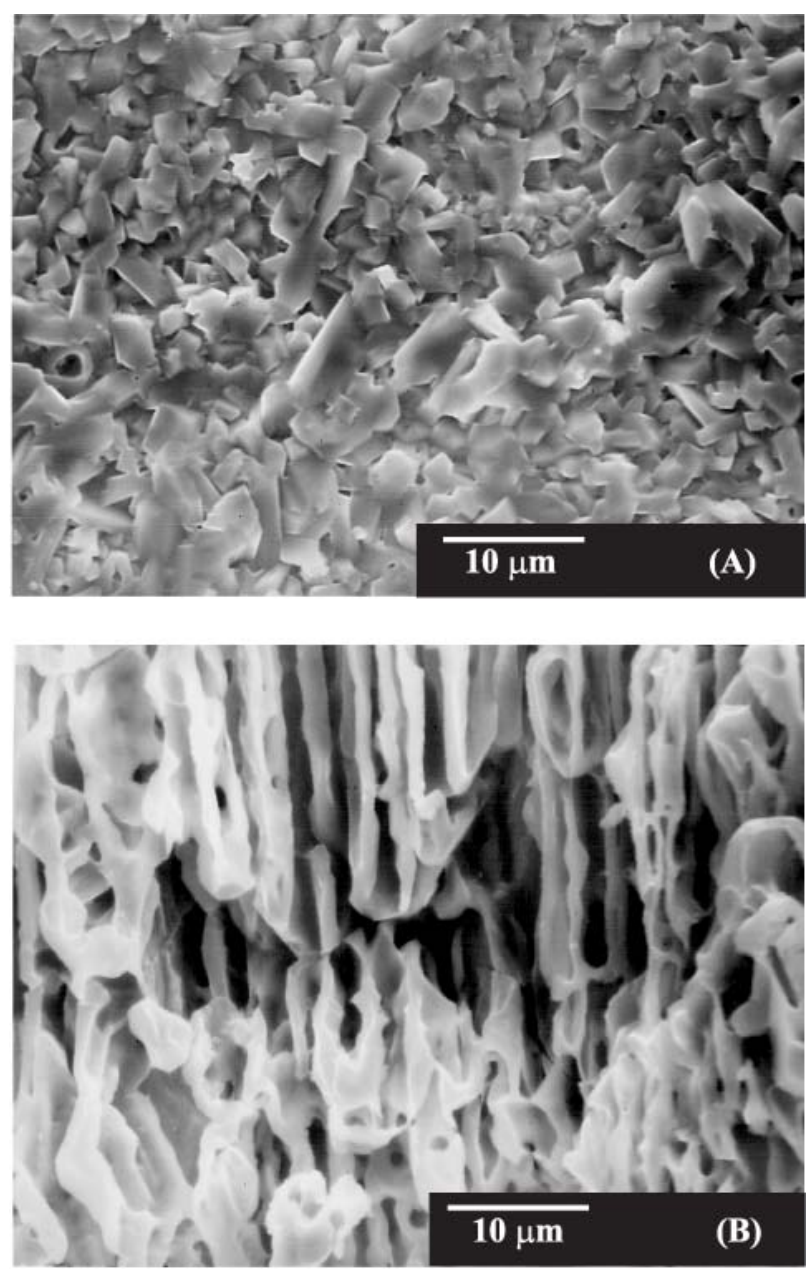

Figure 4. SEM micrographs of the fracture face of (a) gc-LVCP and (b) pgc-LVCP.

The bulk densities of the pg-LVCP and pgc-LVCP, measured by Archimedes's method, are $3.10 \mathrm{~g} \mathrm{~cm}^{-3}$ and $1.76 \mathrm{~g} \mathrm{~cm}^{-3}$, respectively. The apparent density of the ceramic skeleton of the pgc-LVCP is $3.14 \mathrm{~g} \mathrm{~cm}^{-3}$ [for comparison, for the $\mathrm{V}\left(\mathrm{PO}_{3}\right)_{3}$ phase it is $3.03 \mathrm{~g} \mathrm{~cm}^{-3}$ and for the $\mathrm{Ca}_{3}\left(\mathrm{VO}_{4}\right)_{2}$ phase it is between $3.17-3.50 \mathrm{~g} \mathrm{~cm}^{-3}$ depending on the polymorph]. In the apparent density it is just considered the occupied volume by the ceramic skeleton in the monolith. The leachability is the measure of the occupied volume for the soluble phases that constitute the gc-LVCP. Therefore, the leachability correspond the porosity presented by the pgc-LVCP. The leachability is calculated using the equation:

Leachability $=\left(1-\frac{\rho_{\text {bulk }}}{\rho_{\text {apparent }}}\right) \cdot 100$ 
where, $\rho_{\text {bulk }}$ is the bulk density and $\rho_{\text {apparent }}$ is the apparent density of the pgc-LVCP. Therefore, the gc-LVCP exhibits leachability up to approximately 45 vol.\%.

In summary, the preliminary data reported here allows us to conclude that fabrication of porous glass-ceramic monoliths with skeleton of $\mathrm{V}\left(\mathrm{PO}_{3}\right)_{3}$ and $\mathrm{Ca}_{3}\left(\mathrm{VO}_{4}\right)_{2}$ and having a three-dimensional network structure using vanadium phosphate glass as precursor, was obtained and is reported here for the first time. The pgc-LVCP can be a promising porous host for ICS the because $\mathrm{Ca}_{3}\left(\mathrm{VO}_{4}\right)_{2}$ phase has ferroelectric and luminophor properties ${ }^{19,21}$ while the $\mathrm{V}\left(\mathrm{PO}_{3}\right)_{3}$ phase exhibits magnetic property associated with high degree of mechanical, chemical and thermal stability. ${ }^{14}$ Further studies are being carried out in our laboratory aimed at the stoichiometric determination of the phases as well as the control of composition phases and the use of these porous materials as host for integrated chemical systems.

\section{Acknowledgment}

The authors are grateful to Prof. D.L.A. Faria and Prof. M.L.A. Temperini (IQ-USP, Brazil) for the Raman measurements and to Prof. C.H. Collins (IQ-UNICAMP, Brazil) for English revision. This is a contribution of the Millennium Institute for Complex Materials (PADCT/ MCT).

\section{Reference}

1. Cassagneau,T.; Hix, G.B.; Jones, D.J.; Maireles-Torres, P.; Rhomani, M.; Rozière, J.; J. Mater. Chem. 1994, 4, 189.

2. Bard, A.J.; Integrated Chemical Systems - An Approach to Nanotechnology, Wiley : New York, 1994.

3. Gimenez, I.F.; Alves, O.L.; J. Braz. Chem. Soc. 1999, 10, 167.

4. Maia, D.J.; Zarbin, A.J.G.; Neves, S.; De Paoli, M.A.; Alves, O.L.; Quim. Nova 2000, 23, 204.

5. Kumar, K.N.P.; Appl. Catal. A 1994, 119, 163; Kumar, K.N.P.; Keizer, K.; Burggraaf, A.J.; J. Mater. Sci. Lett. 1994, 13, 59.
6. Mazali, I.O.; Alves, O.L.; J. Phys. Chem. Solids, submitted.

7. Schmelzer, J.; Möller, J.; Slezov, V.V.; J. Phys. Chem. Solids, 1995, 56, 1013.

8. Mazali, I.O.; Ph.D. Thesis, Universidade Estadual de Campinas, Brazil, 2001.

9. Kokubu, T.; Yamane, M.; J. Mater. Sci. 1985, 20, 4309.

10. Hosono, H.; Abe, Y.; J. Non. Cryst. Solids 1995, 190, 185.

11. Gimenez, I.F.; Mazali, I.O.; Alves, O.L.; J. Phys. Chem. Solids 2001, 62, 1251.

12. Mazali, I.O.; Alves, O.L.; J. Mater. Sci. Lett. 2001, 20, 2113.

13. Mazali, I.O.; Barbosa, L.C.; Alves, O.L.; J. Mater. Sci. 2004, 39, 1987.

14. Rojo, J.M.; Mesa, J.L.; Calvo, R.; Lezama, L.; Olazcuaga, R.; Rojo, T.; J. Mater. Chem. 1998, 8, 1423; Middlemiss, N.; Hawthorne, F.; Calvo, C.; Can.J. Chem. 1977, 55, 1673.

15. Joint Committee on Powder Diffractions Standards. For $\beta-\mathrm{Ca}_{2} \mathrm{P}_{2} \mathrm{O}_{7}$ card 20-24; $\beta-\mathrm{Ca}_{3}\left(\mathrm{PO}_{4}\right)_{2}$ card 32-176; $\mathrm{Ca}_{3}\left(\mathrm{VO}_{4}\right)_{2}$ card 46-756; $\mathrm{V}\left(\mathrm{PO}_{3}\right)_{3}$ card 33-1442; $\mathrm{VPO}_{4}$ card 34-1336; $\mathrm{LiCaPO}_{4}$ card 14-403.

16. Krasnenko, T.I.; Andrianova, L.V.; Zolotukhina, L.V.; Fotiev, A. A.; Inorg. Mater. 1998, 34, 733; Nord, A.G.; Åberg, G.; Stefanidis, T.; Kierkegaard, P.; Grigoriadis, V.; Chem. Scr. 1985, $25,212$.

17. Waal, D.; Hutter, C.; Mater. Res. Bull. 1994, 29, 1129.

18. Kristallov, L.V.; Fotiev, A.A.; Tsvetkova, M.P.; Russ. J. Inorg. Chem. 1982, 27, 1714.

19. Grzechnik, A.; Chem. Mater. 1998, 10, 1034; Leonidov, I.A.; Leonidova, O.N.; Surat, L.L.; Kristallov, L.V.; Perelyaeva, L.A.; Samigullina, R.F.; Russ. J. Inorg. Chem. 2001, 46, 268.

20. Stranford, G.T.; Condrate, R.A.; J. Solid State Chem. 1984, 52, 248.

21. Grzechnik, A.; Solid State Sci. 2002, 4, 523.

Received: April 30, 2004

Published on the web: August 10, 2004

FAPESP helped in meeting the publication costs of this article. 